On his free weekends he took from its patent holster the black sidearm, clicked off the safety half-way across the back lot, and sat -we could see him, his legs dangling over the edge of the roof-sat on the hencoop.

After the first round or two the chickens stayed inside and gossiped the thunder above their witless heads; he would shoot, and the hens echo, and another shellcase shine in the hot sun-the yard a litter of brass and dung.

Flies. Green flies were what he murdered from his perch, brushing them from his face, scowling them down to earth, taking aim. He hammered them into the dirt, into the wood frame the wire was nailed to. Hours this lasted-weekends.

At the start we had thought it was the rats that raided the coop from time to timeand it all made sense: noise, and the panic of the fowls, the killer in his khaki shirt sitting at ease on the roof, waving the sun from his eyes.

When it was not rats, we saw this was none of our affair and got used to it-weekdays 
called him Sir and envied him ribbons and rank. So what if the chickens choked to death on the spent casings, and men working nights got no sleep?

\section{A PASTORAL FOR INSTITUTIONS}

The pleasures of being mad are common knowledge; right off the top of your head, you

could name fifteen or twenty: the high sense of yourself is one-every madman his own

Voodoo doll, every lunatic his own gleeful inquisitor. Or the utter deep privacy

of the shuttered mind-that's two-where the only visitor is the devil possessing you.

Or the world's attentiveness -clinicians, barbers, wivesthat's three through seven,

though the numbers matter less than you might have thought, and the order not at all. 